\title{
The Analysis Of Lecturer Knowledge For Implementation To The Effective Classroom
}

\author{
Meita Maharani \\ Akademi Teknik dan Keselamatan Penerbangan Surabaya
}

\begin{abstract}
The purpose of this study was to implementation lecturers' knowledge about effective classroom and their classroom practices for teaching English. It was also knowing the correspondence between lecturers' knowledge and the practices. This study designed using qualitative case study approach. The data was obtained using multiple-choice typed test, observation checklist, and interview. The subjects were four English lecturers and their cadets as supporting subject. The data obtained was analyzed using interactive model proposed by Miles and Huberman. The data revealed that the subjects had variety of knowledge about classroom; one of them had sufficient knowledge, another one showed average result and the other two were emerging. In their classroom practice, two lecturers performed effective classroom skill, but the other two showed average effort in managing their class. For the correspondence, it was found that there were three group of lecturers; the first group has sufficient knowledge and applied it simultaneously, the second group has average knowledge but applied it in more effective ways, and the third group has emerging knowledge and applied it likely to be the same as their knowledge in the classroom practice.
\end{abstract}

Keywords: effective classroom, knowledge, implementation

\section{INTRODUCTION}

Schools are the fundamental socio- instructional institutions where the teaching learning activity is implemented in a formally organized manner. Hence, the primary purpose of schooling in one way or another is to serve its clients, which are the cadets, so that they could get the necessary atmosphere to express the desired behavioral changes in their entire personalities. Therefore, to bring such essential intentions to an end successfully, the effective establishment of the classroom instruction is significantly important.However, the crucial issue that currently demands the attention and commitment of most scholars in education is the question of how instructional effectiveness in classrooms which having large and diversified learners could consistently be maintained.

As a matter of fact, beginning from early days till now a good large number of individuals in the field of education have been observed exerting their enormous amount of human, material and financial resources in the arena to suggest valid and reliable solution for the issue being raised. Unfortunately, however, none of them still seem to be bold enough to put instructional effectiveness in a nutshell presuming that it would be secured merely through the formulation of sound curriculum. Even the best curriculum and the most perfect syllabus remain dead unless quickened into life by the right methods of teaching (Aggrawal, 1996-79).

However, though the right methods of teaching are employed, as Callahan and Clark (1988-128) noted, the lecturer's classroom effort will totally be useless if the learners' attitudes are opposed towards classroom learning. Supporting this concept, Dunkin and Biddle (in Mohammed, 2002) said that of the classroom learning forms a necessary condition for learning and if the lecturer cannot solve problems in this domain we can give the rest of teaching away. Therefore, classroom ability of a lecturer, as the main person behind the teaching learning process, is the key answer in encountering the issue being raised.

Few aspects of education have generated as much concern as classroom and organization. Classroom strategies have a strong potential to positively influence on cadets' achievement and learning. There are many studies indicating that classroom is one of the crucial factors that influence learning. Effective classroom prepares the classroom for an effective instruction, which is crucial for the progress of learning. The term classroom has been defined differently by various educators throughout the history. In most 
general terms, classroom refers to the actions and strategies that lecturers use to maintain order (Doyle, 1986). Martin, Yin and Baldwin (1998) define classroom as a broader and comprehensive construct that describes all lecturer efforts to oversee a multitude of activities in the classroom including learning, social interaction and cadets behaviors. Classroom constitutes three broad dimensions; person, instruction and discipline (Martin \& Baldwin, 1993). By maintaining an effective classroom, a lecturer will make his best effort in constructing a supporting and good learning environment for the cadets. Recently, many studies have been accomplished related to the significance of classroom to support the learning process in the classroom.

One of the result revealed that classroom is a very important aspect to be applied in elementary classroom (Cotter, 2011). Elementary education is the starting point where the cadets could construct their belief about their knowledge and learning. Hence, it is thought to be appropriate to introduce the cadets in this level with a well-managed classroom in order to help them in building their organized routines for their learning. Furthermore, the elementary cadets need an orderly and comfortable place in order to learn and perform at their best. A poorly managed classroom cannot run smoothly, which results in an environment that prevents cadets from having the opportunity to learn to their highest potential. An elementary school classroom should have a positive and enjoyable atmosphere, while also functioning as an active learning environment. Classroom also is crucial to necessary happenings in the school day such as safety and communication.

Unfortunately, however, in its implementation, lecturer has figured out that it is hard to differentiate the strategy of how to manage the class and to manage cadets' discipline (Cotter, 2011). Mostly, lecturer relates classroom with classroom discipline that could be used as tool to build, maintain, and form good behavior. This fact impacts on the establishment of the rule that contains consequences that in fact do not significantly help the cadets in achieving their learning goal. Those kinds of lecturers fail to understand that classroom is a skill to manage all aspects in the classroom to prevent any misbehavior that could disrupt the classroom activities. Hence, it is more than just a tool to make the cadets sit still and be silent in the classroom as what it is expected by the lecturer but it is all about creating such situation that supporting the cadets in learning instead of misbehaving.

The problem related to the implementation of effective classroom could happen in any level of education to any subjects, unexceptionally to English class in elementary school. As a foreign languagelearning subject, English could either be exciting or frightening for the cadets especially for those in primary education. Therefore, the ability of the English lecturer in managing the classroom and creating supporting atmosphere is mainly required for the effectiveness of the instruction. Realizing the significances of effective classroom to support English teaching and learning process in elementary classroom, it was thought to be important to hold a well-structured and detail investigation about the lecturers' knowledge and practices of effective classroom especially in an elementary school as the topic of this study.

Having the topic like it was mentioned, this study was conducted in the form of case study, which will be done in a private school in Surabaya. The school being chosen for this study was ATKP Surabaya due to the popularity of this school that attracts many parents to enroll their kids to study in this school. Knowing that this school has big amount of cadets with a well-known title in the community, was raising a big curiosity in the researcher's mind about the way the English lecturers' strategy in managing the big classes so that the cadets could achieve their learning goals. Hence, this study was accomplished to answer the curiosity and also found out some other insight about the lecturers' knowledge about classroom in which applied effectively in their practices. Finally, completing this investigation, the correspondence of lecturers' knowledge to their practices was also studied systematically; hence the report was a holistic result of investigation.

\section{TYPES OF ARTICLE}

This article was brief result of a case study held in its attempt to investigate lecturers' knowledge about classroom and its practices in the classroom setting also about how the correspondences to each other. The study designed using a qualitative case study approach in which the study was done in ATKP Surabaya. It is hoped that this article could enrich the knowledge of English educators, especially those who teach elementary school about the nature, significance, and also strategies of effective classroom. This study was referring 
to some related articles and studies although this topic was considered as rarely investigated topic. Therefore, it is expected that this could inspire further research in the same field/ focus.

\section{METHODS}

This study was designed using qualitative case study approach in which it was used to described and interpreted lecturers' knowledge and practices about effective classroom in Merriam (2001) described a case study as a means to deeply understand a situation and the meaning to those involved. Therefore, this kind of design was in line with the purpose of the study that was investigating closely the knowledge and application about classroom owned by the lecturers in the chosen setting. Using qualitative case study approach, this study had four English lecturers in ATKP Surabaya as the subjects of the study. These subjects were chosen through a purposive sampling technique that is a kind of sampling technique in which the researcher could decide the subject to be included in the case being studied. The reason of choosing those subjects was because the researcher wanted to have variation of the results of study although they work in similar institution. Besides, for the purpose of enriching and validating the data, the cadets being taught by the subjects of the study had also been involved as secondary subjects.

In order to reach the objectives, this study applied some qualitative methods to collect the data. There were three qualitative methods of data collection utilized in this study, namely; test, observation, and interview. The test used was a non parametric test in which the test was constructed for the sake of gaining data about the study and could not be generalized for all population. This non- parametric test was constructed to check lecturers' knowledge about effective classroom. There were 35 items of questions for the test in which this test was multiple choice type tests. The participants were given some choices and also some terms to be used to fill in the blanks in the questions, although some of them were also in the form of true and false questions. Hence, test used in this study was used to answer the research problem number one about lecturers' knowledge about classroom. The next one was observation in which in this study it had been applied after accomplishing the test. This complete observer observation was used in order to document behavioral patterns of the cadets while lecturer applied certain classroom strategy, comprehensively record the lecturers' classroom practices, and later obtain deeper data or information that could be used to form questions for interview session. Therefore, the second research problem was answered properly by this method, which was about the application of classroom for teaching in the classroom. The third method was focused group interview in which it was like common interview but it was more likely to be grouped based on categories decided by the researcher. In this study, the interview was addressed to three different groups, which were focused group, focused directed group, and groups of cadets. Focus group was a group of lecturer(s), which categorized in the first and second quadrant of the matrix. Those lecturers were applying 50-100\% knowledge that they had fully in their teaching practice. While focused directed interview was focused for digging information from groups of lecturers that had limited knowledge and applied it insignificantly so that they were placed in the bottom part of the quadrant. Meanwhile, cadets' interview was mainly about general comments on their lecturers' performances and personal comments on the problems faced in the class by both lecturers and cadets. Therefore, the interviewees here are the four lecturers who are the subjects of the study and some cadets as supporting participants. The interview session would be able to answer the research question number three about the correspondence of lecturers' knowledge about effective classroom and its practice in the classroom. The data that obtained in this method is in the form of description and explanation based on the interviewees' thought, idea, and experiences that lead by the list of questions built by the researcher for the interview.

Finally, the data gained through a series of data collection processes was analysed using interactive model of data analysis proposed by Miles and Huberman (1994). This kind of data analysis method involved three simultaneous flows of activity which aimed at drawing representative result of a study. The three activities were; data reduction, data display, and conclusion drawing/ verification. Data reduction referred to a process of selecting, focusing, simplifying, abstracting, and transferring any information that is gathered from the process of data collection. Then those data gathered from data reduction were displayed or visualized in order to ease the researcher to draw conclusion about the study. Having all data displayed, it was the time for the researcher to draw conclusion about the study based on the data gained. Furthermore, the 
conclusion was verified by asking back the subjects about the reliability and validity of the data. Hence all the result of the study was fair for both the researcher and the subjects. Using this kind of data analysis, the researcher could steadily moves among these four areas (in which data collection was the other one) in order to draw well-structure and purposeful based conclusion or result of study.

\section{FINDINGS AND DISCUSSIONS}

This section gives an overall picture of the findings of this study by bringing together the major findings from the individual lecturers. The section begins by lecturers' knowledge about effective classroom, lecturers' classroom practices, and correspondence between lecturers' knowledge and practices about effective classroom.

Lecturers' Knowledge about Effective Classroom in this study, it could be reported that all of the subjects have sufficient knowledge about nature of classroom proposed by Doyle (1986). They all agreed that classroom refers to how order is established and maintained in classroom environment. Besides, they also showed understanding toward the importance of classroom in teaching and learning process; that is to provide cadets conducive learning environment, support classroom activities to achieve learning goals, provide great learning opportunity for the cadets, help the lecturer in building confidence and self- esteem in delivering knowledge in front of the classroom. Those were all correct options related to the importance of classroom although the subjects could only answer one or two points. The nature of classroom also related to a description of a classroom that is well managed or even poorly managed by the lecturer. The subjects agreed that it is not necessary for the cadets to be silent, passive or strictly follow the rules made by the lecturer, but it is more likely to be internal motivation of the cadets to learn at their best supported by conducive situation made by the lecturer using any strategies and facilities.

The next point, which needs to be known by a lecturer as classroom manager is about qualities of effective classroom managers. Talking about characteristics of effective classroom managers both personally and professionally, all four subjects showed mastery on but then when it was arrived to a part, which asked them to differentiate the definition of the two qualities confusion was arisen. All subjects thought that personal quality refers to the things that lecturer likes to do in classroom and professional quality refers to all jobs required by government. In fact, personal quality, based on the theory, could be defined as personality value of a lecturer about the class, while professional quality refers to the ability of a lecturer as professional educator. From this point, it could be said that the subjects only have practical understanding for this point not the theoretical one although these two understanding should be mastered simultaneously by the lecturers.

After knowing the qualities required by an effective classroom manager, the subjects were also asked about approaches in classroom in which the subjects mostly made mistakes. All subjects had failed in defining a term classroom approach in which all of them answered as any strategies to maintain relationship among lecturers and cadets in the classroom instead of knowing it as styles used by lecturers in managing order in classroom. The definition made by the subjects brought impact on their knowledge in mentioning types of

approaches in classroom . Two subjects among four answered that the approaches consisted of behaviorism, constructivism, relativism in which those are kinds of approach in education, one of them answered by inductive, deductive and productive, which have no relationship to classroom approach. Only one subject answered correctly by mentioning interventionist, non- interventionist, and interactionalist although in the next item about the fact that there is no any best approach used in all occasion but depends on the situation and condition of the class. When the subjects were assigned to label the columns that consisted of some characteristics of the approaches, three out of four lecturer mislabeled it by outing interactionalist in the characteristics of interventionist and vice versa but not in the point of non-interventionist. It means that overall the subjects used different kinds of approaches in managing their classroom but they did not know about the technical terms used in presenting it based on the theory stated by Doyle (1986).

Variation of answers found in the next indicator which was about strategies in classroom that includes seating arrangement, establishment of rules and procedures, giving cadets sense of purpose, time, motivation, and communication skill. All four subjects could list some strategies in managing classroom although none of them ticking the boxes of all strategies provided by the theory. In its relation to seating 
arrangement, lecturer 4 failed in describing each pattern since she thought that there was no specific type of seating arrangement. But then, a weird result shown in the next item when they were asked to label some pictures by the name of seating patterns, lecturer 2 and 3 who answered previous question correctly could not label it correctly. Hence three of them mislabeled the pictures by stating that row pattern as cluster, and cluster as round table and vice versa. The next three items were about the establishment of rules and procedures in which in the part that they need to define the terms, lecturer 1,2, and 3 defined rules as statement to regulate cadets behavior and procedures are the ways lecturer teaching in the classroom. In fact, based on the theory, rules refers to statements to regulate form of individual conduct in the classroom while procedures are ways of taking various duties or rights in the classroom, hence those terms did not only address to the cadets but all individual involved in teaching and learning process. Although, most of them found it was hard to define the terms, but all of them could still recognize the importance of having it in the classroom that is to maintain discipline. However, lecturer 2 and 3 failed in recognizing the things lecturer should do to establish rules and procedures in the classroom. Instead of answering the inappropriate answer, these two lecturers answered the correct one that is reminding the class of the rules at any times rather than when someone misbehaved, make different rules and procedures for different activities.

Classroom strategies also involve the part of teaching when the cadets were given sense of purposes. Mostly all subjects had knowledge about the definition of this term, but then when they were asked to state the importance of it, three lecturers made a mistake. Lecturer 2, 3, and 4 stated that by giving cadets sense of purposes, it will just let them know about the lesson, in fact it aimed at having the cadets on track in doing things in the classroom. The failure of the subjects in recognizing the importance of giving sense of purpose, affected their knowledge on describing situation in which purposes were not given. Lecturer 2 and 3 were answering this question by stating that if there is no sense of purposes given by a lecturer, the lecturer and the cadets will do some activities related to the topic. There was a possibility that the subjects felt that the question was unclear or it could be because they did not understand the impact. The next discussion was related to time as part of classroom. Three among four lecturers stated that the more time available for a lecturer to teach, the better the result of the learning. However, lecturer 4 thought that it was not about amount of time provided to support cadets' achievement, but it is more on the effectiveness of the teaching and learning process itself. In deciding type and definition of phases in time, lecturer 1 though that time in classroom could be divided into beginning, middle and end instead of beginning, transition, pacing, wait time and closure. Besides, some of the subjects found that the definition of each phase of time is confusing although in fact they understood what it supposed to like in classroom practice.

The next point was about managing cadets' motivation as part of classroom. In defining the nature of motivation, two lecturers thought that motivation refers to cadets' efforts in achieving their goal in learning instead of cadets' commitment to their classroom learning that shows desired classroom performances. However, these four subjects had sufficient understanding about the importance of motivation and also the behaviors indicates highly motivated cadets in its relation to classroom. Similar thing happened to the next item, which was about strategies to work with lowly motivated cadets, but lecturer 4 chose different option in which it might be caused by misunderstanding of that lecturer toward the question. Another indicator in classroom strategies that should be considered is about communication skill of the lecturer. Three out of four lecturers, however, understood communication as a process of talking about things to exchange idea. In fact, in the theory and in its relation to classroom, communication refers to process of sending message both verbally and nonverbally to affect others' behavior or action. Moreover, two lecturers out of four identified kinds of communication in different way in which they stated that communication in the classroom was only referring to verbal and nonverbal communication but only one way communication. It could show that these two lecturer known that classroom communication would only come from the lecturer but not the cadets in return. But then, when the subjects were asked to label the column, which contained characteristics of communication, they could answer it accordingly. The last bit of point in classroom was about factors that make classroom ineffective. The subjects showed sufficient understanding about any factors meant by the questions although in the last question when they were asked to choose strategies to deal with these factors, they answered it differently, which might be caused by misunderstanding toward the question.

In short, there was variety of knowledge about classroom found among four subjects due to different results fond from the test. There were some indicators that troubled all lecturers to be answered in which 
about theoretical terms, definitions, and also characteristics. However, in some questions that required practical understanding all lecturers had gained sufficient knowledge about it. Misunderstanding of the subjects toward the questions could cause other mistakes made by lecturers. Therefore, it was thought that some question need to be revisited and clarified to be so clear for the subjects.

\section{Lecturers' Classroom Practices}

There found variation of score in the observation about lecturers' classroom practices in which it means that each lecturer applied some points in indicators in their own way. In the first indicator, which was about whether, the lecturer taught in an ideal classroom, all four lecturers have got score 1. It was because all of them taught in a class with more that 35 cadets in a small size classroom with only 1 adult to help them in learning. Having this kind of class, it would affect the achievement of the cadets and the availability of the lecturer to support each cadet with their own problems and diversity. The next indicator was about the application of lecturers' knowledge about classroom in general and its significances. Lecturer 1 and 4 had got full score in this indicator due to their performances that fulfilled all points requires in it, meanwhile lecturer 2 and lecturer 3 was gained 2 score. The next point was about characteristics of an effectively managed classroom with cadets' performances as the indicator. One lecturer out of four had gained full score, in which one more gained two and the next two had made 1 score. In terms of personal and professional qualities of the lecturers as classroom managers, almost all lecturers performed sufficient proofs on their personal and professional qualities. Lecturer 1 had made full score in both indicators, but lecturer 2 and lecturer 3 had made average scores in both indicators and lecturer 4 showed average performance on the personal quality but full score in the professional quality. Classroom approach was also an important aspect to be seen in classroom practice in which there was possibility that each lecturer was only using one approach in a lesson but could be combination of two or three. Hence, the score gained based on the observation of two lessons. In this case, lecturer 1made 3 scores due to the use of two different approaches correctly in proper situation and activities, lecturer 4 gained score 2 for the use of combination of two approaches but one was dominant and the approaches used not really used effectively, while lecturer 2 and lecturer 3 only gained 1 score due to the use of one approach but still this approach did not use maximally and the lecturer showed unclear cut for the approach used. In terms of classroom strategies, lecturer 1, 2, and 3 gained 2 scores since they did not perform some parts of the strategies, like; establishing rules and procedure, time, motivation and strategy in coping with lowly and highly motivated cadets. However, lecturer 4 gained score 3 for doing maximum effort to apply all the strategies. At last, in its relation to the ways lecturer dealt with factors that make classroom ineffective, all four lecturers had gained two scores since they had most likely similar strategies to face problems in the classroom.

After observing the four subjects, it could be concluded that lecturers' practices about effective classroom were different from one lecturer to another due to some factors. The first one was about their

knowledge about classroom itself, then their personal feeling and adjustment related to what kinds of situation that they have on field, and finally about condition of the cadets and classroom in certain time especially at the time of the research.

\section{Correspondence between Lecturers' Knowledge and Practices about Effective Classroom}

From the study, the four lecturers who teach English in ATKP Surabayam could be divided into three different groups. The first group was a lecturer with sufficient knowledge about effective classroom and then the knowledge applied simultaneously in the teaching practice. The lecturer who involved in this group was lecturer 1, which means that in her teaching practice in its relation to classroom was basically based on the knowledge she had gained from any sources like; theory from college, material from workshop, information from reading and other adjustment from the case happened in the field. However, there were still problems she faced in dealing with the factors that make classroom ineffective so that it became constraints for her to improve her performances in the class. The problems face were like big numbers of cadets with little space of classroom in which it made it hard for her to do many different activities in different lesson, limited time provided to deliver the material for the cadets, and facilities to support the teaching and learning process. 
The second group found in this study was the one who has average amount of knowledge related to classroom but then in the application she performed sufficient strategies in managing classroom. There was one lecturer who could be categorized to be the member of this group that was Lecturer 4 . The average knowledge that she has in terms of theoretical understanding of classroom could be caused by her background education that she had had which was from English literature instead of education. Therefore, she did not get specific lesson about classroom in order to know all terms and aspects in classroom . However, this kind of lecturer mostly used her personal value and adjustment to deal with cadets and other factors in classroom. The value and also the adjustment could be gained from sharing idea and experiences with other lecturers and also her willingness to know about the cadets that she taught. Similar to the first group, this lecturer also found that it was an obstacle when she needs to deal with big size class with limited sources, limitation of time provided for her to teach, and one different aspect was about her confidence in becoming model for her cadets in communicating using English in front of the classroom. The last group was consisting of two lecturers; those were lecturer 2 and lecturer 3 in which they were categorized in this group due to limited knowledge they have which later affected their performances in classroom practices. Although these two lecturers had been teaching for some years but still their knowledge was under the average. It could be caused by their background education so that they did not get any specific material about classroom. The other reason of their emerged level of knowledge was because they did not use their time to improve themselves by reading articles, joining workshop or other efforts to support their understanding. Actually their performances in classroom practices in the classroom showed their consistency in which the less knowledge they had, the less effective their classroom would be.

In short, it could be stated that the amount of knowledge that a lecturer has related to classroom would affect their classroom practices although some personal feelings and adjustments could also affect differently. It was possible that the lecturer simultaneously applied the knowledge that they have into practice, but then it was also possible that the lecturer did not have sufficient knowledge about the theoretical terms in classroom but actually they had applied in the classroom.

\section{CONCLUSION AND SUGGESTION}

Classroom is an important aspect to be considered by lecturer in order to support cadets in learning at highest level. Having an effectively managed classroom would not only increase lecturers' confidence in teaching, but also providing cadets a conducive learning environment so that it could create meaningful learning for them. However, in real life practice, the application of classroom was still experiencing some constraints from any sides; the schools, the lecturers and also the cadets. The schools sometimes could not provide both the lecturer and the cadet any facilities or even policies which could support them in conducting the teaching and learning process. Besides, the lecturers' knowledge about classroom itself could be another obstacle for their teaching practices. Sometimes, when a lecturer does not have sufficient knowledge about classroom or other content that they need to be mastered, they could not that easy to maintain the class and give good model for cadets for their learning. Although in the teaching practices, lecturers could do some adjustment using their personal value or feeling as educators, but still in order to maximize the support for the cadets, they need to provide themselves with knowledge or recent issues related to it. The last obstacle could come from the cadets' side in which they have less motivation in learning, which cause misbehavior shown in the teaching learning process. This misbehavior actions, if it is not managed properly could cause ineffectiveness of learning in which it could disadvantage them for their achievement. Hence, when these three parties work together supporting each other, it could be beneficiary for all those three and later would bring good impact toward the cadets' future, the quality of education in the country and of course in the development of the country itself. This study tried to investigate a case happened in certain place in its relation to classroom practices based on the knowledge of the lecturers in order to support the learning process of the cadets. Specifically, it tried to figure out the knowledge of the lecturers about classroom , then how the knowledge applied into practice by the lecturers themselves in classroom setting. Later the correspondence among those two would be shorted and hopefully the results could be insight for the lecturers as well as the school to improve their educational quality in one aspect, which is classroom . 
ATKP Surabaya was the place where the study had been done due to its quality and accreditation as a good primary school in Surabaya. There were four English lecturers being observed in this study for their knowledge and classroom practices. By using the media of test, observation checklist, and interview guidelines, some facts and data revealed from both lecturers and cadets' sides. It was found out that those four lecturers had variety of educational background, personal and professional qualities as a lecturer, which then could bring some effects toward their knowledge about classroom . Among these four, one of them had sufficient knowledge about classroom, another one showed average result and two others were still emerging. Those results were found by the help of a multiple-choice typed test, which was mainly based on the theory of classroom by Doyle (1986). In accordance to the test, a list of observation indicators were made in order to score lecturers' classroom practices. As the result, the lecturer who has sufficient knowledge about classroom had got likely similar score in her classroom practices. She applied the knowledge that she has simultaneously although some aspects could be improved in such a way. Then, another lecturer who had average knowledge about classroom, however, performed more than what she knew in her classroom practice. She could manage the classroom well although still some improvements were still needed especially in the technical aspect. Other two lecturers, had shown average performance in their classroom practices, but coherently with their test' results.

After gaining all the results both from the test and the observation checklist, this study was finding the correspondence of the knowledge and classroom practices of these four subjects. It was found that there were at least three group of lecturers in which the first group who has sufficient knowledge about classroom and applied it simultaneously, the second group has average knowledge about classroom but applied it in a more effective way, and the third group who has emerging knowledge about classroom and applied it a little bit more or likely to be the same as their knowledge in the classroom practice. It also found out that the application of lecturers' knowledge about effective classroom could be caused by the way lecturer did personal adjustment in the field and their concern about their teaching which need a big support from the school in terms of facilities, class size and numbers of cadets. In sum, it could not be said for sure that a lecturer has sufficient knowledge about classroom will apply it sufficiently in their classroom practice due to some other supporting aspects in the field.

After gaining some results of the study about lecturers' knowledge and practices about classroom, there are some suggestions that could be given to the lecturers in specific and the school, other educators, and other parties who concern on education. For the lecturers, both the subjects and other lecturers, it is hoped that they could improve their knowledge about classroom although they have learnt in brief about it in college. There are many ways that the lecturers could do in improving their knowledge about classroom, like; reading articles about classroom especially the recent update from certain educational institution, joining workshop in its relation to classroom, sharing experiences with colleagues so that it could help us to understand varies types of cadets, and many others. Having good knowledge about classroom, it is hoped that the lecturers could apply it simultaneously in their teaching practice. Hence, the effectively managed class would be more dynamic and conducive to support cadets in showing their potential at the highest level. For the school, it will be good idea to make certain rules, procedures, and also wisdoms in its relation to teaching and learning process especially to classroom in order to help lecturer to be on track in their classroom practices. The third suggestion is addressed to other educators or parties who concern about education to improve the quality of people and especially children in the country. These parties could involve in this process by providing lecturers in any level by more intensive workshops, conferences or even meeting time so that they could share recent issues about anything related to education in general and classroom in specific. Besides, it would be a great idea if they could provide mini library in each school together with the parents or school's committee so that there will be no reason for the lecturers to not improve themselves since they have been provided by good quality of books, articles, or other journals. Inviting some experts in education (could be foreigners for English) for a visit so all schools in turns to at least provide the lecturer with real examples of how classroom could be managed or how material delivered differently from what they have been practiced everyday. Having enough references both passive and active ones, it is hoped that lecturers could be more enthusiastic in teaching and sharing knowledge with the cadets and in accordingly the cadets would have greater motivation in learning 


\section{REFERENCE}

Aggrawal, J.C. 1996. Principles, Methods and Techniques of Teaching. New Delhi: Vikas Publishing House, LTD.

Callahn, J.F and Clark, L.H. 1988. Teaching in The Middle and Secondary School (3rd ed). New York: McMillan Publishing Company.

Cotter, Kayla. 2011. Proper Classroom is Essential for an Effective Elementary School Classroom. Honors Theses of Roger Williams University.

Doyle, W. 1986. Classroom organization and. In M. C. Wittrock (Ed.). Handbook of research on teaching (3rd ed.). New York: Macmillan.

Martin, N. \& Baldwin, B. 1993. Beliefs regarding classroom style: The differences between pre- service and experienced lecturers. Paper presented at the annual meeting of the Mid-South Educational Research Association. Knoxville, TN.

Martin, N., \& Yin, Z. 1998. Attitudes and beliefs regarding classroom style: Differences between male and female lecturers. Paper presented at the annual meeting of the Southwest Educational Research Association. Austin, TX.

Merriam, S.B. 2001. Qualitative Research and Case Study Applications in Education. San Francisco: JosseyBass.

Miles, M. B., \& Huberman, A. M. 1994. Qualitative data analysis: An expanded sourcebook. Thousand Oaks, California: Sage.

Mohammed, Ibrahim. 2002. Classroom Strategies In The Benishangul-Gumuz National Regional State Secondary School. Thesis of Department of Curriculum And Instruction Faculty of Education Addis Ababa University. 